\title{
TINJAUAN KETIDAKLENGKAPAN PENGISIAN CATATAN MEDIS PADA BERKAS REKAM MEDIS RAWAT INAP PASIEN PENDERITA DIABETES MELITUS TERHADAP KLAIM BPJS DI RUMAH SAKIT UMUM IPI MEDAN TAHUN 2018
}

\author{
1. Fitriyani Lubis; ${ }^{2 \cdot}$ Khairina Rizki \\ 1. Dosen APIKES Imelda, Jalan Bilal Nomor 52 Medan; ${ }^{2}$ Alumni APIKES Imelda
}

E-mail: ${ }^{1 .}$ fitriyanilubis38@gmail.com

\begin{abstract}
ABSTRAK
Menurut Permenkes 2008, Rekam medis adalah berkas yang berisikan catatan dan dokumen tentang identitas pasien, pemeriksaan, pengobatan, tindakan dan pelayanan lain yang telah diberikan kepada pasien dan dapat di pergunakan untuk persyaratan klaim BPJS. Tujuan dari penelitian ini untuk mengidentifikasi ketidaklengkapan pengisian catatan medis terhadap klaim BPJS. Jenis penelitian yang digunakan bersifat deskriftip kualitatif dengan metode wawancara, observasi. Penelitian ini dilakukan di Rumah Sakit Umum IPI Medan pada bulan Mei-Juni 2017. Populasi dari penelitian ini berjumlah 1 orang petugas dan 11 berkas rekam medis pasien penderita diabetes melitus, dengan sampel 1 orang petugas dan 11 berkas rekam medis pasien penderita diabetes mellitus. Teknik analisa data dalam penelitian ini adalah analisa data secara deskriptif. Hasil penelitian dari 11 berkas rekam medis rawat inap pasien penderita diabetes melitus memiliki Angka Ketidaklengkapan yang berjumlah lengkap 8 (72,8\%) berkas dan tidak lengkap 3 (27,2\%) berkas yang terdiri dari hasil LAB, laporan operasi, daftar pemberian obat. Saran Penulis kepada bagian instalasi unit rekam medis Rumah Sakit Umum Imelda Pekerja Indonesia untuk saling bekerjasama dalam melengkapi berkas khusunya pada catatan medis berkas Rekam Medis pasien penderita Diabetes Melitus agar prosedur dalam klaim BPJS dilaksanakan dengan lancar dan tidak terkendala.
\end{abstract}

Kata Kunci: Ketidaklengkapan, Rekam Medis, BPJS, Rawat Inap, Diabetes Melitus.

\section{PENDAHULUAN}

Rumah sakit adalah sarana kesehatan yang menyelenggarakan kegiatan layanan kesehatan serta dapat di manfaatkan untuk pendidikan tenaga kesehatan dan penelitian. Pelayanan kesehatan yang di laksanakan di rumah sakit meliputi rawat jalan, rawat inap, pelayanan gawat darurat, pelayanan medik, pelayanan penunjang medik dan non medik (Depkes, 2002).

Rekam medis adalah berkas yang berisikan catatan dan dokumen tentang identitas pasien, pemeriksaan, pengobatan, tindakan dan pelayanan lain yang telah diberikan kepada pasien. Rekam medis mempunyai berbagai kegunaan yaitu sebagai bukti perjalanan penyakit pasien dan pengobatan yang telah diberikan, alat komunikasi diantra dokter dengan tenaga kesehatan lainnya yang memberikan pelayanan dan pengobatan kepada pasien, sumber informasi dalam pengumpulan data statistik kesehatan (Permenkes, 2008).

Rekam medis harus segera dibuat dengan lengkap setelah pasien menerima pelayanan. Hal ini dijelaskan tentang rekam medis dalam pasal 5 ayat 1 menyatakan bahwa setiap dokter dalam menjalankan praktik kedokteran wajib membuat rekam medis dan ayat 2 rekam medis sebagaimana dimaksud pada ayat 1 harus dibuat segera dan dilengkapi setelah pasien menerima pelayanan. Rekam medis yang lengkap akan memudahkan penyediaan informasi bagi pihak rumah sakit. Rekam medis yang lengkap dapat digunakan sebagai refrensi pelayanan kesehatan, menunjang informasi, 
membantu penetapan diagnosis dan prosedur pengkodean penyakit. sedangkan rekam medis yang tidak lengkap akan menghambat penediaan informasi. Oleh karena itu kelengkapan pengisisan pada berkas rekam medis merupakan hal penting mengingat kegunaan dari isi rekam medis (Permenkes, 2008).

BPJS kesehatan adalah badan hukum yang di bentuk untuk menyelenggarakan program jaminan sosial oleh pemerintah yang mana jaminan sosial adalah salah satu bentuk perlindungan sosial untuk menjamin seluruh rakyat agar dapat memenuhi kebutuhan dasar hidupnya yang layak yang mana bertujuan untuk mewujudkan terselenggaranya pemberian jaminan dan terpenuhinya kebutuhan dasar hidup yang layak bagi setiap peserta dan atau anggota keluarga, jadi dapat di simpulkan BPJS merupakan badan publik yang bertanggung jawab pada presiden dan berfungsi menyelenggarakan program jaminan kesehatan bagi seluruh penduduk Indonesia termasuk orang asing yang bekerja paling singkat 6 bulan di Indonesia (Anwar, 2014).

Program BPJS di Rumah Sakit antara lain program jaminan kecelakaan kerja, program jaminan kematian, program jaminan hari tua, dan program jaminan pensiun. Kelengkapan catatan pada berkas rekam medis di lihat dari segi kelengkapan dokumen berkas rekam medis berupa diagnosis, tindakan atau prosedur apabila ada, serta hasil-hasil pemeriksaan yang berguna untuk mendukung penegakan diagnosa. Dokumen rekam medis di katakan lengkap dengan syarat jika terdapat tanda tangan dokter, diagnosis, diagnosis tindakan atau prosedur yang di lihat pada resume pasien, pemeriksaan penunjang seperti hasil lab. Namun kelengkapan data dalam klaim tidak hanya melihat dari kelengkapan isi dari dokumen rekam medis itu sendiri tetapi ada kelengkapan administrasi ini tidak lengkap maka dapat mempengaruhi pada persetujuan verifikator seperti kelengkapan kartu kepesertaan pasien jamkesmas, surat rujukan, surat pernyataan rekam medis peserta jamkesmas (Supriyanto, 2003).

Berdasarkan penelitian (Mahyunita, 2011) yang berjudul Ketidaklengkapan pengisian catatan medis dan pengisian formulir berkas rekam medis diagnosa Diabetes Melitus di Rumah Sakit Sambanglihum tahun 2011 dari hasil penelitian pencatatan berkas rekam medis hanya sedikit angka yang tidak lengkap baik dari dokter ataupun perawat seperti catatan pemberian obat berjumlah lengkap 66,5 berkas $(48,9 \%)$ tidak lengkap 68,5 berkas $(51,12 \%)$ dan kelengkapan hasil LAB berjumlah lengkap 112 berkas $(83,58 \%)$ tidak lengkap 22 berkas $(16,42 \%)$.

Berdasaran survey awal di Rumah Sakit Umum Imelda Pekerja Indonesia Medan, angka ketidaklengkapan catatan medis berkas rekam medis pasien penderita diabetes melitus di Rumah Sakit Umum Imelda Pekerja Indonesia medan pada bulan mei-juni dari 10 berkas rekam medis pasien yang kembali ke instalasi rekam medis, terdapat 7 berkas rekam medis yang tidak lengkap dan 3 rekam medis yang lengkap. Hal ini dilihat dari kelengkapan pengisian catatan terintegrasi pasien kelengkapan pengisian resume medis (Ringkasan masuk dan keluar) serta hasil-hasil pemeriksaan penunjang (laboratorium, kardiologi, CT.scan dan lainya).

Berdasarkan latar belakang di atas maka penulis tertarik untuk membuat penelitian dengan judul "Tinjauan Ketidaklengkapan Pengisian Catatan Medis Pada Berkas Rekam Medis Rawat Inap Pasien penderita Diabetes Melitus terhadap Klaim BPJS di Rumah Sakit Umum Imelda Pekerja Indonesia Medan Tahun 2018'.

\section{Tujuan Penelitian}

Adapun yang menjadi tujuan dalam penelitaian ini adalah untuk Untuk mengidentifikasi ketidaklengkapan pengisian catatan pada berkas rekam medis rawat inap pasien penderita Diabetes Melitus medis terhadap klaim BPJS di Rumah Sakit Umum Imelda Pekerja Indonesia Medan periode Mei-Juni tahun 2017.

\section{Manfaat Penelitian}

1. Bagi Rumah Sakit

Dapat di gunakan sebagai bahan atau informasi untuk penilaian pelayanan kesehatan dan peningkatan kinerja 
petugas khususnya di unit klaim BPJS di masa yang akan datang.

2. Bagi Institusi Pendidikan

Sebagai referensi/ bahan materi pengajaran di APIKES Imelda Medan dan untuk penelitian serta bahan pertimbangan bagi mahasiswa Rekam Medik dan Informasi Kesehatan (RMIK) atau bagi pihak lainnya yang memerlukan.

3. Bagi penulis agar dapat menerapkan teori dengan permasalahan yang penulis temukan sehingga dapat menambah wawasan berfikir dalam melaksanakan tugas rekam medik yang profesional.

\section{METODE}

\section{Jenis Penelitian}

Jenis Penelitian yang digunakan penulis dalam penelitian ini dengan metode bersifat deskriftip kualitatif, dimana penulis akan memahami fenomena tentang yang di alami oleh subjek penelitian terhadap klaim BPJS di Rumah Sakit Umum Imelda Pekerja Indonesia tahun 2017 (Moleong, 2007). Metode dalam penelitian ini adalah menngunakan metode observasi, dimana observasi adalah proses pengamatan dan pencatatan secara sistematis mengenai gejala-gejala yang di teliti (Saryono, 2013).

\section{Waktu Penelitian}

Waktu penelitian di lakukan pada bulan Mei-Juni 2017.

\section{Tempat Penelitian}

Penelitian ini di lakukan di Rumah Sakit Umum Imelda Pekerja Indonesia (RSU IPI) Medan di bagian rekam medis dan BPJS pada bulan mei- juni tahun 2017 .

\section{Populasi}

Populasi merupakan keseluruhan sumber data yang di perlukan dalam suatu penelitian (Dwi Anggeraini dan Saryano, 2013). Dalam penelitian ini yang menjadi populasi adalah petugas koding di ruang BPJS yang berjumlah 1 orang dan berkas rekam medis rawat inap pasien diabetes militus periode Mei-Juni Tahun 2017 yang berjumlah 11 berkas rekam medis di Rumah
Sakit Umum Imelda Pekerja Indonesia Medan.

\section{Sampel}

Sampel merupakan objek yang di teliti dan di anggap mewakili seluruh populasi (Notoatmodjo, 2012). Dalam penelitian ini seluruh populasi yang di jadikan sampel (Total sampling) berjumlah 11 berkas rekam medis rawat inap pasien penderita diabetes militus dan 1 orang petugas koding di ruang BPJS di Rumah Sakit Umum Imelda Pekerja Indonesia Medan.

\section{Teknik Sampling}

Teknik sampling yang di gunakan dalam penelitian ini adalah teknik total sampling, yaitu pengambilan sampel secara keseluruhan. Hal ini berarti setiap anggota populasi itu mempunyai kesempatan yang sama untuk diambil menjadi sampel.

\section{Definisi Operasional}

Untuk membatasi ruang lingkup atau pengertian yang di amati atau di teliti, perlu sekali hal tersebut di beri batasan atau definisi operasional (Notoatmodjo, 2012).

1. Resume Medis

Ringkasan atau catatan medis selama pasien di rawat di rumah sakit mulai dari pasien penderita diabetes mellitus tersebut masuk rumah sakit hingga pulang dari rumah sakit.

2. Pemeriksaan Penunjang

Segala sesuatu tindakan yang di lakukan terhadap pasien untuk menunjang tegaknya suatu diagnosa.

3. Pemeriksaan Diagnostik Diabetes Melitus

Pemeriksaan penunjang untuk memastikan diagnosa diabetes mellitus meliputi pemeriksaan Glukosa Urin, Kadar Gula Darah, Tes Toleransi Glukosa Oral, Hemoglobin Glukasi.

4. Daftar Pemberian Obat

Pemberian obat yang telah di lakukan kepada pasien selama mendapatkan perawatan di rumah sakit sesuai dengan diagnosa yang di derita pasien.

\section{Metode Pengumpulan Data}

1. Data Primer 
Data primer merupakan data atau fakta yang di peroleh secara langsung oleh pengolah data. Contoh nya data-data yang di dapatkan dari hasil survey tentang kelengkapan pengisian lembar atau catatan medis pada berkas rekam medis pasien diagnosa diabetes melitus, atau survey tentang kepuasan pasien terhadap layanan yang di berikan di fasilitas pelayanan kesehatan (Budi, 2011).

2. Data Skunder

Data sekunder merupakan data dan fakta yang di peroleh dari orang lain sehingga sumber data yang di gunakan dapat berupa catatan, register, rekam medis, sistem informasi di fasilitas pelayanan kesehatan, kartu indeks, dan sensus.

Contohnya untuk mengetahui mutu kelengkapan berkas rekam medis dapat di lakukan penelitian menggunakan data skunder berupa berkas rekam medis untuk mengecek kelengkapan berkas rekam medis setelah pasien pulang selesai mendapatkan pelayanan di fasilitas pelayanan kesehatan (Budi, 2011).

3. Data Tersier

Data tersier merupakan data yang di peroleh dari para ahli, para penulis atau penelitian (Rustiyanto, 2010).

\section{Teknik Pengolahan Data}

Dalam pengolahan data menurut Notoatmodjo (2012). Pengolahan data di lakukan dengan melihat presentase data yang terkumpul kemudian diolah dengan langkah-langkah sebagai berikut:

\section{Editing}

Data yang diperoleh akan diperiksa dan dilakukan pengecekan kesalahan data dan kekeliruan dalam pengumpulan data melalui kuesioner yang telah di kumpul.

2. Coding

Dilakukan penomoran pada setiap lembar kuesioner.

\section{Entry}

Pemasukan jawaban-jawaban dari responden yang telah di isi .

4. Cleaning
Semua data dari detiap data atau responden selesai dimasukkan, maka perlu dicek kembali untuk melihat kemungkinan-kemugkinan adanya kesalahan kode ketidaklengkapan, dan sebagainya, kemudian dilakukan pengoreksian.

\section{HASIL}

Hasil penelitian yang diperoleh setelah melakukan pengambilan data yang dilakukan dengan dua jenis yaitu wawancara langsung kepada petugas koding BPJS dan pengambilan data dari berkas rekam medis rawat inap pasien diabetes militus.

Hasil yang diperoleh dari wawancara bahwa syarat klaim BPJS untuk berkas yang harus ada antara lain, berupa:

1. Surat Eligibitasi Pasien (SEP)

2. Kartu Keluarga

3. Rujukan IGD/ Perintah Opname

4. Ringkasan Keluar (Resume Medis)

5. Lepas Rawatan

6. Daftar Pemberian Obat

7. Pemeriksaan Penunjang Medis (Lab, Radiologi, PA, CT-Scan, Dll)

8. Laporan Operasi jika dibutuhkan/jika dilakukan pembedahan.

Data diperoleh dari hasil wawancara bahwa syarat klaim BPJS untuk kelengkapan catatan medis pada rekam medis rawat inap pasien diabetes militus antara lain berupa ; terisinya dengan lengkap catatan terintegrasi pasien pada rekam medis, adanya dilakukan pemeriksaan diagnostik yang menunjang dokter untuk tegaknya suatu diagnostik.

Kalau untuk pasien dengan diabetes militus pada umumnya dengan pemeriksaan KGD (Kadar Gula Darah), kemudian obat yang dikonsumsi oleh pasien tersebut harus disesuaikan juga dengan diagnosa yang diderita oleh si pasien. Untuk klaim BPJS pada umumnya di Rumah Sakit Imelda Pekerja Indonesia Medan petugas analisa data memeriksa kelengkapan catatan pada rekam medis rawat inap setelah dipulangkan dari ruang rawat inap baik berupa analisa kualitatif dan kuantitatif. Jika masih ada lembar rekam medis yang tidak lengkap maka rekam medis tersebut akan 
dikembalikan ke ruang pelayanan rawat inap masing-masing.

Tabel 1. Persentase Ketidaklengkapan Catatan Medis Pada Berkas Rekam Medis Rawat Inap Pasien Diabetes Militus di Rumah Sakit Umum Imelda Pekerja Indonesia Medan tahun 2017

\begin{tabular}{ccc}
\hline $\begin{array}{c}\text { Berkas Rekam } \\
\text { Medis Rawat } \\
\text { Inap Pasien } \\
\text { Diabete Militus }\end{array}$ & Frekuensi & $\begin{array}{c}\text { Persentase } \\
(\mathbf{\%})\end{array}$ \\
\hline Lengkap & 8 & 72,8 \\
\hline Tidak Lengkap & 3 & 27,2 \\
\hline Total & $\mathbf{1 1}$ & $\mathbf{1 0 0}$ \\
\hline
\end{tabular}

Tabel di atas menunjukkan bahwa distribusi ketidaklengkapan catatan medis pada 11 berkas rekam medis pasien penderita Diabetes Melitus tidak lengkap berjumlah 3 berkas $(27,2 \%)$ yang terdiri dari hasil LAB, Laporan operasi, dan Daftar pemberian obat sedangkan berkas yang lengkap berjumlah 8 berkas $(72,8 \%)$.

\section{PEMBAHASAN}

Setelah dilakukan penelitian mengenai ketidaklengkapan catatan medis pada berkas Rekam Medis Rawat Inap pasien Diabetes Militus, maka dapat disimpulkan bahwa berdasarkan tabel 4.1 diatas hasil penelitian yang telah dilakukan oleh peneliti dengan 11 berkas rekam medis Rawat Inap pasien Diabetes Militus dan 1 orang petugas koding BPJS, maka di peroleh 8 berkas $(72,8 \%)$ berkas Rekam medis yang lengkap dan 3 berkas $(27,2 \%)$ berkas yang tidak lengkap yang terdiri dari hasil laboratorium, laporan operasi, daftar pemberian obat.

Ketidaklengkapan catatan medis dapat menyebabkan terlambatnya pengklaiman BPJS dan terjadinya penumpukan berkas yang akan di klaim oleh petugas koding BPJS (Fantri pamungkas, 2013).

Berdasarkan observasi penulis menemukan bahwa keterlambatan klaim BPJS karena tidaklengkapnya catatan persyaratan klaim antara lain seperti: Surat Eligibitasi Pasien (SEP), Kartu Keluarga, Rujukan IGD/perintah opname, Ringkasan keluar, Lepas Rawatan, Daftar Pemberian Obat, Pemeriksaan Penunjang Medis (Lab, Radiologi, PA, CT-Scan, Dll), Laporan
Operasi jika dibutuhkan/jika dilakukan pembedahan.

Dan untuk kelengkapan catatan medis Khususnya pasien penderita Diabetes Millitus antara lain harus terisinya dengan lengkap catatan terintegrasi pasien pada berkas rekam medis, seperti pemeriksaan diagnostik, jika pada pasien Diabetes Militus pada umumnya dilakukan pemeriksaan KGD (Kadar Gula Darah), penyesuaian obat yang di konsumsi oleh pasien, dengan adanya catatan klinis khususnya setiap pasien penderita Diabetes Militus mampu memberikan penjelasan atas terjadinya perawatan dan hasil perawatan terhadap kelancaran klaim BPJS.

Kelengkapan pengisian catatan medis pada berkas rekam medis oleh tenaga kesehatan akan memudahkan dalam memberi tindakan kepda pasien. Selain itu juga sebagai sumber data pada bagian rekam medis dalam pengolahan data yang kemudian akan menjadi informasi yang berguna bagi pihak manajmen dalam menentukan langkah-langkah strategis untuk pengembangan pelayanan kesehatan (Depkes, 1997).

Ketidaklengkapan catatan medis merupakan hal yang begitu penting karena juga sangat berpengaruh terhadap proses pelayanan dan mutu rumah sakit, ketidaklengkapan ini dapat menyebabkan terjadinnya keterlambatan dalam proses pengklaiman di rumah sakit (Pamungkas, 2013).

\section{KESIMPULAN}

Berdasarkan hasil penelitian dan pembahasan yang berjudul "Tinjauan Ketidaklengkapan Catatan Medis Pada Berkas Rekam Medis Rawat Inap Pasien Diabetes Militus Terhadap Klaim BPJS Di Rumah Sakit Umum Imelda Pekerja Indonesia Medan tahun 2017”. Dapat disimpulkan dari 11 berkas rekam medis rawat inap pasien penderita diabetes militus lengkap berjumlah 8 berkas $(72,8 \%)$ dan tidak lengkap 3 berkas $(27,2 \%)$. ketidaklengkapan persyaratan catatan medis menyebabkan proses pada klaim BPJS terlambat dan terjadinya penumpukan berkas 
di unit BPJS sehingga petugas harus mengembalikan rekam medis tersebut kesetiap ruangan rawat inap masing-masing dan memakan waktu.

\section{SARAN}

1. Saran kepada petugas analisa rekam medis agar lebih memperhatikan catatan medis sebelum dilakukanya proses untuk kelengkapan klaim di unit BPJS.

2. Saran kepada perawat di ruang rawat inap agar lebih memperhatikan tiap-tiap lembar rekam medis sebelum di serahkan keruangan klaim BPJS dan lebih di tingkatkan kembali kerja sama antara petugas kesehatan terkait terlaksananya proses klaim BPJS.

\section{DAFTAR PUSTAKA}

Aditama, YT. (2003). Manajemen Administrasi Rumah Sakit. Edisi ke-2. Jakarta: UI-Press.

Arikunto, Suharsimi. (2006). Prosedur Penelitian Suatu Pendekatan Praktik. Jakarta: Rineka Cipta.

Budi. (2011). Rancangan Penelitian dan Jenis Penelitian. Diakses pada 13 Juni 2017 Jam 13.00 WIB. Http://digilib.unimus.ac.id.

Departemen Kesehatan RI. 1997. Sistem Kearsipan Rekam Medis.

Edna, K Huffman. (2008). Helth Information Managment. Http://salsabravol.wordpress.com.

Kemenkes dan Anwar. (2014). Badan Penyelenggara Jaminan Sosial. Diakses 15 Juni 2017 Jam 15:20 WIB. Http://www.academia.edu/10779736/B PJS.

Komalawati. (1999). Peranan Informed Consent Dalam Transaksi Terapeutik. Bandung: Citra Aditiya Bakti.

Moleong. (2007). Metode Penelitian Kesehatan Kualitatif. Jakarta: Graha Ilmu.
Muninjaya. (2004). Manajemen Pelayanan Kesehatan. Diakses: 20 Juni 2017 Jam 12.25 WIB. Https://www.belbook.com.

Notoatmodjo. (2012). Pengertian Poppulasi dan Sampel. Diakses 15 Juni 2017 Jam 17,10 WIB. Https//www.slideshare.net.

Pamungkas, Fantri. (2013). Analisis Ketidaklengkapan Pengisian Catatan Medis berkas Rekam Medis di RS. PKU Muhammadiyah Yogyakarta. Yogyakarta: UGM.

Permenkes No.269/Menkes /Per/III/2008. Tentang Rekam Medis.

Rustiyanto, E. (2009). Etika Profesi Perekam Medis dan Informasi Kesehatan, Yogyakarta.

Saryono dan Anggeraini. (2013). Metodelogi Penelitian Kualitatif dan Kuantitatif dalam Bidang Kesehatan. Yogyakarta: Nuha Medika.

Sumantri. (2011). Metode Penelitian Kesehatan. Edisi Pertama. Jakarta: kencana 2011.

Supriyantoro. (2013). Badan Penyelenggara Jaminan Sosial dan Jaminan Kesehatan. Diakses: 15 Juni 2017 jam 15.12 WIB. Https://bpjskesehatan.go.id.

Undang-Undang Republik Indonesia No. 24 Tahun 2011 tentang Badan Penyelenggara Jaminan Sosial. Https://mewarisgagasan.wordpress.com

Wolper dan Pena, Gustini. (2011). Pengertian Rumah Sakit. Diakses: 15 Juni 2017 Jam 20.30 WIB. Https://aepnurulhidayat.wordpress.com.

World Health Organization. (2013). Definisi Diabetes Militus. Diakses: 20 Juni 2017 Jam $13.11 \quad$ WIB. Http://etd.repository.ugm.ac.id.

Yaslis, Ilyas. (2003). Tentang Penagihan Klaim Berkas Rawat Inap. Diakses: 15 Juni 2017. Jam 15.45 WIB. Http//UEUundergraduate-684.pdf. 